\title{
CAREER PATH
}

\section{Chris Lipinski}

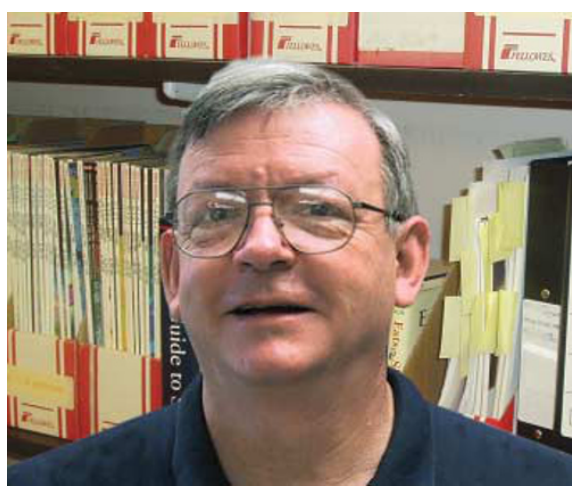

Chris Lipinski, formulator of the 'rule of five' and Senior Adjunct Research Fellow at Pfizer's Groton laboratories, has successfully held a senior role in the pharmaceutical industry but has remained unencumbered by managerial responsibilities. He has followed a career path that allowed him to do something he really enjoys, and urges young scientists to do the same.

As a student, Lipinski was interested in the biological applications of chemistry and soon abandoned his medical studies, ultimately earning his Ph.D. in physical organic chemistry. "The principles that I was learning kept coming up in drug-industry literature, and got me interested in that field, but I knew I didn't have enough synthetic chemistry experience." Thanks to National Institute of General Medical Sciences postdoctoral funding from the US National Institutes of Health (NIH), Lipinski got the opportunity to work in Bob Ireland's synthetic chemistry laboratory at Caltech. "In general I am more a supporter of the private sector than the public sector but this particular NIH program helped me personally and this kind of opportunity for young scientists is exactly what the NIH should be funding."

Lipinski's only career regret is not publishing early. "It's important - your career is in your hands, and there's no assurance that the company you start working with will be the same company you retire with. Publishing is a great educational tool: it makes you go through the intricacies of the science, you have to review the literature and you go through the peer-review process. I think it really makes you a better scientist."

Frustrated with the conservative publication policy at Pfizer in the mid-1970s and having had applications to two prestigious conferences turned down, Lipinski decided to try and beat the obstacles in the Pfizer publication system of that era, and sought the advice of Joe Lombardino, an experienced medicinal chemist. "I greatly respected Joe and he had a very sound publication record. He told me there were some tricks you could use. So I started writing review articles and working in collaboration with people in other departments - work that was not part of any official Pfizer project specification."

It was at this time that Lipinski learned another useful attribute for the industrial scientist - information sharing. "A particularly influential manager, Hans-Jürgen Hess, Director of Medicinal Chemistry at Pfizer at that time, once said to me, 'If you want something from somebody, go to them with something first. Be outgoing and volunteer information, and be helpful even when there's no immediate payback, because somewhere along the line you might need a favour."

Another senior chemistry manager, Chuck Harbert, encouraged Lipinski to study the physical property measurements of drugs as a sideline. "It was in 1990 and our project was going very slowly. I explained my frustration to Chuck and was surprised when he asked what he could do to help." He indulged Lipinski's interests by providing US $\$ 30,000$ on the condition that he find his own lab space and temporary scientific manning, and present his work regularly to the departmental management. "The scientific culture at Pfizer was fairly permissive — so as long as you weren't wasting your time, there was no problem." Later on, Harbert invited Lipinski

\section{"Publishing is a great educational tool ... I think it really makes you a better scientist."}

to a meeting that ultimately led to the concept of the 'rule of five'. "There was a meeting of pharmaceutical scientists and chemistry managers, and Chuck wanted me to attend. I heard this litany of horror stories about the poor solubility of compounds coming out of our medicinal chemistry laboratories and knew we had to work on this. That meeting turned my entire lab around." Without asking for permission, he used his contacts and, in a conversation over hotdogs and sauerkraut with a developer at a Pittcon meeting, determined the specifications for the first automated solubility apparatus in the industry. "It was very primitive, but it worked, and we ran that assay for about 1,000 compounds. As a scientist you have to take the responsibility to go ahead with an idea — had this gone down in flames, I would have had to bear responsibility for it."

Despite being retired for two-and-a-half years, Lipinski speaks to us from his Pfizer office. It's a testament to how much he has enjoyed his career, and something he says is important for young scientists to consider. "Early on in your career you want to get exposed to as many fields as possible. Many organizations now support continuing education, which is a great way to explore different disciplines. Then, when an opportunity arises to hybridize between fields, you're in a good position to take it."

One thing that has changed since Lipinski joined Pfizer is the long-term career prospects for medicinal chemists. "When I joined Pfizer, starting as a medicinal chemist in a large pharmaceutical company meant you could expect to end your career there. I don't think you can count on that any more." With more of an onus on individuals to do their own career planning, it is also more important for young chemists to increase the breadth of their skill sets. "When I did my postdoctoral research, molecular genetic sciences did not exist, yet now it is increasingly a part of discovery research, especially with the advent of biomarkers." The interaction between chemistry and genomic disciplines means learning a completely different vocabulary and appreciating cultural differences, too. However, Lipinski thinks it's worth it: "There is more satisfaction and the team concept is more widespread than before. Many organizations have migrated away from departments separated by discipline. At Groton, there are no separate chemistry, biology or molecular genetics departments - everybody works in teams, which makes the local successes much more satisfying."

For medicinal chemists, the dream is to discover a drug. Lipinski did not achieve this directly, but he contributed a useful principle that might help others discover many drugs. He now intends to get involved in promoting data sharing between industry and academia, which he hopes will set a precedent for addressing other 'log-jams' in research. "Instead of criticizing the patent system or arguing about discovering drugs for profit, maybe we can begin to build bridges by starting at a technical level. I'm very excited about that." 